\title{
Psychosocial factors and mental health in cancer patients: Opportunities for health promotion
}

\author{
H. Boer , W. J. L. Elving \& E. R. Seydel
}

To cite this article: H. Boer , W. J. L. Elving \& E. R. Seydel (1998) Psychosocial factors and mental health in cancer patients: Opportunities for health promotion, Psychology, Health \& Medicine, 3:1, 71-79, DOI: 10.1080/13548509808400591

To link to this article: https://doi.org/10.1080/13548509808400591

曲 Published online: 24 Oct 2007.

Submit your article to this journal $\pi$

Џ Article views: 53

Q View related articles $₫$

4 Citing articles: 8 View citing articles 


\title{
Psychosocial factors and mental health in cancer patients: opportunities for health promotion
}

\author{
H. Boer, W. J. L. Elving \& E. R. SEYDEL \\ Department of Psychology, University of Twente, Enschede, The Netherlands
}

\begin{abstract}
A$ first step in planning health promotion with respect to mental health is analysing the factors that influence mental health. Diagnosis of the relevant variables may contribute to the design of effective health promotion programmes. In this paper the relationship between psychosocial factors and mental health status of cancer patients is discussed. The study investigates the relation between psychosocial factors like social support, generalized self-efficacy, feelings of loneliness, social mobilization and mental health among cancer survivors $(\mathrm{n}=480)$. Results reveal that mental health in cancer survivors is slightly lower than in a reference group from the general population. Generalized self-efficacy and feelings of loneliness are the major psychosocial factors related to mental health in cancer survivors. The implications for the design of health promotion activities using self-efficacy theory are discussed.
\end{abstract}

\section{Introduction}

Effective health promotion programme require firm footing in the behavioural sciences and their conceptual foundations (Seydel et al., 1994). Such foundations permit knowledge to be cumulative rather than sporadic and lessons learned in one project to be applied to other areas. The effectiveness of health promotion programmes depends heavily on the quality of planning. In planning health promotion programme health professionals can be guided by implicit criteria, vague assumptions or by trial and error. Planned health promotion is a form of planned behavioural change. Behavioural change not only refers to actual behaviour but also to the cognitive or social determinants of behaviour. A first step in planning health promotion is an analysis of the determinants of the health status of the patient. With respect to mental health, a planned health promotion programme would first require an analysis of the mental health status of the patients and its determinants. The aim of this article is to provide an analysis of the psychosocial factors related to the mental health status of cancer patients. Assessing the relative importance of psychosocial factors in the mental health status of cancer patients can contribute to the design of effective health promotion programmes aimed at reducing psychosocial problems or promoting mental health in cancer patients.

An important aspect of cancer is that the stage of the illness can have an important influence on the mental health status. In the disease process of cancer patients, 4

Address for correspondence: Dr Henk Boer, Department of Psychology, University of Twente, PO Box 217, 7500 AE Enschede, The Netherlands. Tel: +31534893291. Fax: +31534894259. E-mail: h.boer@wmw.utwente.nl 
stages can be distinguished (Weisman, 1977). During the first stage, the stage of diagnosis and medical treatment, existential problems are vital. In the second stage, the stage of adaptation, the patient tries to re-assume daily life. The third stage consists of the remission of the disease and possible metastases of the disease. In the fourth stage of the disease, the terminal stage, cure is not possible anymore. Not every patient passes through all these stages. In some patients with a poor prognosis the diagnostic stage is followed by the terminal stage. Patients who survive cancer only go through stages one and two.

In the various stages cancer patients can experience a sequence of symptoms and psychosocial problems (Knobf, 1990: Schag et al. 1990; Weisman, 1977). With regard to psychosocial problems cancer is a disease which, more than most other diseases, disorders the psychic balance from the beginning of the disease. The patient can be overwhelmed by feelings of despair, panic and other emotions and in the other instances experience severe feelings of depression and apathy (Cassileth et al., 1984). Feelings of uncertainty are common among cancer patients, for example about the results of treatments and about the expectation for the future (Dunkel-Schetter, 1984; Peters-Golden, 1982; Wortman, 1984). Bodily symptoms related to the disease or the treatment of the disease are an important aspect of the disease burden of cancer patients. Cancer patients sometimes undergo stressful medical treatments like chemotherapy or radiotherapy, which can have severe side effects (Holland \& Lesko, 1988; Silberfarb et al., 1980).

The mental health status of cancer patients is mostly studied assessing the severity of psychosocial problems or by containing mental health status in the broader concept of quality of life. Most studies are descriptive in nature and up till now research has not provided a clear insight into the contribution of objective and subjective factors to the successful adaptation to the disease (Friedman et al., 1989). The main aim of this paper is to provide insight into the role of psychosocial factors in the mental health of cancer patients.

The study that is reported in this paper uses a research model inspired by the stresscoping model of Lazarus (1966). According to the research model, the mental health status is the result of the objective disease status of the patient, of the subjective disease burden and of the intrapersonal and extrapersonal resources that can be used by the patient to overcome the burden posed by the disease. The research model was used as a framework for ordering the dependent and independent variables.

The first component contained in the research model is the objective health status of the patient. The objective health status of the patient refers to several indicators that give an impression of the medical condition of the patient. Possible indicators are the type of diagnosis (with or without metastases) and the medical prognosis about the course of the disease.

The second component of the research model refers to the appraisal of the severity of the disease by the patient. The third component of the research model represents the internal coping resources of the patient, i.e. the appraisal of the patient of the possibilities of control in the threatening situation. The appraisal of the possibilities of control are crucial in the process of psychological adaptation in breast cancer patients (Taylor et al., 1984). The appraisal of the possibility of control in a certain situation closely resembles the notion of self-efficacy (Bandura, 1986). Self-efficacy is the expectation of an individual to successfully perform certain behaviour. Bandura links self-efficacy to certain specific behaviours. Research has shown that an individual develops a certain level of generalized self-efficacy on the basis of either successful or negative experiences (Jeruzalem \& Schwarzer, 1992; Schwarzer \& Fuchs, 1996). Because every cancer patient can experience specific adaptation problems in various areas, a strengthening of the level of generalized self-efficacy could imply a strengthening of the possibilities of the cancer patient to cope with individual problems one 
encounters in the course of the disease process (Rowland, 1988). In their study among 273 cancer patients, Cunningham et al. (1991) found a positive correlation between the level of generalized self-efficacy and quality of life and mood. From their study they concluded that generalized self-efficacy positively influences the use of adaptive coping strategies and hence the level of adaptation to the disease.

External resources can also facilitate the process of adaptation. Social support is one of these external resources (Funch \& Metlinn, 1982; Northhouse, 1988; Smith et al., 1985). Social support of professionals is mainly effective if they provide information about the disease and about the prognosis (Ros et al., 1992; Zemore \& Shepel, 1987). Loneliness as the representation of the lack of social support may also be a valid operationalization of the external coping resources of the patient.

This paper describes a study designed using the research model of the role of psychosocial factors in mental health among cancer patients. The study was performed among breast cancer survivors. The aim of the study was to assess quality of life, including mental health among cancer survivors and to assess the influence on quality of life, including mental health, of some psychosocial factors from our research model (generalized self-efficacy, social support, loneliness and demographic characteristics like age and level of education).

\section{Study}

In this study mental health of cancer survivors was studied in the framework of a larger study on the relation between quality of care and quality of life of cancer patients. Mental health was studied as part of the concept of quality of life, which represents an important aim of cancer treatment. In current cancer care, Health related Quality of Life is an important measure in clinical research and patient care (Bruner, 1995). Several self-reporting questionnaires designed to assess quality of life have been developed and psychometrically tested (Brook et al., 1979). Despite the current interest in the assessment of quality of life in the treatment of cancer patients, little is known about factors that may influence it. The aim of this study was to examine factors related to the mental aspects of the quality of life of cancer survivors using the research model described earlier as a framework. Special attention was paid to the relation between psychosocial characteristics of the patients and mental health aspects of perceived quality of life. Psychosocial factors studied were social support, feelings of loneliness, generalized self-efficacy and social mobilization skills.

\section{Method}

\section{Subjects}

The patients participating in this study had been aware of the cancer diagnosis for an average of 2.5 years. Patients had received various medical treatments and were not hospitalized at the time of the study. They were selected by the medical administration department of two general hospitals, according to the following inclusion criteria: knowledge of cancer diagnosis, age between 18 and 80, comprehension of the Dutch language, and treatment at one of the following partnerships: gynaecology (gynaecological cancers, $n=54$ ), surgery (breast cancers, $n=254$ ), lung diseases (lung cancers, $n=39$ ), internal medicine (tumours in the stomach and intestine region, $n=55$ ) and urology (prostate cancer, $n=78$ ).

A total of 480 patients participated in this study, 340 females and 140 males. The average age of the patients was 60.6 years (minimum 20 years, maximum 80 years, $\mathrm{SD}=11.8$ ) 


\section{Questionnaires}

Mental health aspects of Quality of Life of the patients were measured using sub-scales of the RAND-36 (Van der Zee \& Sanderman, 1994), which is a Dutch translation of the MOS SF-36. The psychometric qualities of the RAND-36 were tested in several populations and were sufficient (Van der Zee et al., 1994). In this study, results on sub-scales referring to mental health will be presented: mental health, social functioning, role limitations due to emotional problems and vitality.

Mental Health. This was assessed by 5 items: 'During the last 4 weeks how often (a) did you feel very nervous?, (b) were you so depressed that nothing could cheer you up?, (c) did you feel calm and quiet? and (d) did you feel happy?' Questions could be answered on 5-point scales, with the extremes 'never' and 'continuous'. The scale 'Mental health' was sufficiently reliable (alpha $=0.87$ ).

Social functioning. This was assessed by 2 items: 'During the last 4 weeks, to what extent did your physical health status or emotional problems limit you in you normal social activities with family, friends, neighbours or others?' and 'During the last 4 weeks, how often did your physical health status or emotional problems limit you in your normal social activities with family, friends, neighbours or others?' Questions could be answered on 5-point scales. The scale 'Social functioning' was sufficiently reliable (alpha $=0.75$ ).

Role limitations due to emotional problems. These were assessed by 4 items. Patients were asked whether they had experienced the following difficulties in their work or other daily activities due to an emotional problem, e.g. because you felt depressive or anxious: 'You were able to pay less time to work or other occupations', 'You have attained less than you wanted' and 'You did not do your work or other activities as carefully as you used to.' The scale 'Role limitations due to emotional problems' was sufficiently reliable (alpha $=0.89$ ).

Vitality. This was assessed by 4 items: 'During the last 4 weeks, how often (a) were you enjoying life?' (b) did you feel energetic, (c) 'did you feel exhausted' and (d) did you feel tired?', Questions could be answered on 5-point scales, with the extremes 'never' and 'continuous'. The scale 'Vitality' was sufficiently reliable (alpha $=0.81$ ).

Scores on all sub-scales were transformed to 100-point scores, with a high score implying little problems with that aspect of Quality of Life.

Social support. This was measured with the SSL12-I (Van Eijck et al., 1994). The SSL12-I is the shortened version of the Social Support List-Interaction version, and is especially constructed for use with elderly people. This list measures 3 kinds of support, namely daily support, support with problems and esteem support. Examples of items are: 'Does it ever happen that someone invites you for a party or dinner?' (daily support). 'Does it ever happen that someone gives you good advice?' (support with problems). 'Does it ever happen that someone gives you compliments?' (esteem support). The reliabilities of the 3 social support scales were satisfying (Cronbach's $\alpha_{\text {daily support }}=0.75$; Cronbach's $\alpha_{\text {support with problems }}=0.83$; Cronbach's $\alpha_{\text {esteem support }}=0.82$ ). Respondents had to answer these questions on a 4-point scale, with the alternatives (1) little or never, (2) once in a while, (3) 
regularly, and (4) very often. Scores are presented at a 100-point scale and a high score implies much social support.

Degree of loneliness. To assess this, the Loneliness-Deprivation Scale (DeJong-Gierveld, 1987) was used. This scale consists of 11 items, such as 'I wish I had a really close friend', 'I can rely on my friends whenever I need them', and 'I miss having people around me' (Cronbach's $\alpha=0.89$ ). Patients had to answer on a 5-point scale, with the alternatives: strongly disagree, disagree, not disagree/not agree, agree and strongly agree. Scores are transformed to a 100-point scale, whereby a low score implies much feelings of loneliness and a high score implies no feelings of loneliness.

Generalized self-efficacy. This was assessed with a short version of the Dutch Scale of Generalized Self-efficacy developed by Boer (1993). Example of items are: 'When unexpected problems occur, I don't handle them well' and 'I give up things before completing them'. Patients had to answer on a 5-point scale, with the alternatives: strongly disagree, disagree, not disagree/not agree, agree and strongly agree. The reliability of the generalized self-efficacy scale was high (Cronbach's alpha $=0.81$ ). Scores were transformed to a 100-point scale, where a low score implies that the patient does not find him or herself capable of dealing with new problems or new situations and a high score implying that the patient finds him or herself capable of dealing with new problems or new situations.

Social Mobilization scale. The social mobilization scale (Riemsma et al., 1997) is concerned with how capable are people of mobilization of their social environment for support or help. It consists of 5 items. Examples of items are: ' $I$ am sure that I can find someone to talk about my problems' and 'I am sure that I can find someone to give me practical assistance'. Patients had to answer on 5-point scales, with the alternatives: strongly disagree, disagree, not disagree/not agree, agree and strongly agree. The reliability of this scale was high (Cronbach's alpha $=0.77$ ). Scores were again transformed to 100 -point scores and a high scores implies that the patient finds him or herself capable of mobilizing his or her social environment.

\section{Results}

In Table 1, the mean scores, and standard deviations of the sub-scales of the RAND-36, the social support scales, loneliness deprivation scale, generalized self-efficacy scale and the social mobilization scale are given.

With respect to the mental aspects of quality of life, the mean scores in Table 1 can be compared to the mean scores obtained in a validation study of the RAND-36 (Van der Zee \& Sanderman, 1994). This reference group consists of 1,063 subjects from the general population, with an average age of 44 years (range 18-89). In the reference group the mean score on the sub-scale 'Social functioning' was 86.9. The mean score of the cancer survivors in this study was slightly lower (82.3). In the reference group, the mean score on the sub-scale 'Role limitations due to emotional problems' was 84.1 . The mean score of the cancer survivors in this study was slightly lower (77.1). In the reference group, the mean score on the sub-scale 'Mental health' was 76.8. The mean score of the cancer survivors in this study was slightly lower (72.7). In the reference group, the mean score on the sub-scale 'Vitality' was 67.4. The mean score of the cancer survivors in this study was slightly lower 
Table 1. Mean scores and standard deviations of the mental health sub-scales of the RAND-36, the social support scales, the loneliness deprivation scale, the generalized self-efficacy scale, and the social mobilization scale

\begin{tabular}{lcc}
\hline Scale & Mean score & $\begin{array}{c}\text { Standard } \\
\text { deviation }\end{array}$ \\
\hline Social functioning & 82.3 & 21.9 \\
Role limitations-emotional problem & 77.1 & 37.9 \\
Mental health & 72.7 & 18.0 \\
Vitality & 64.7 & 19.7 \\
Daily support & 64.1 & 17.4 \\
Support with problems & 55.7 & 23.6 \\
Esteem support & 55.9 & 22.3 \\
Loneliness-deprivation & 75.3 & 15.2 \\
Generalized self-efficacy & 64.4 & 17.9 \\
Social mobilization & 76.2 & 15.0 \\
\hline
\end{tabular}

(64.7). In general, the level of psychosocial factors is in the mid-range of the scale. In an absolute sense, scores on the social support scales are slightly above the midpoint of 50 . The mean scores also show that patients experience more daily support than they experience support with problems or esteem support. Patients do not report many feelings of loneliness and find themselves moderately capable of dealing with new problems or new situations (generalized self-efficacy). Finally, patients find themselves capable of mobilizing support or help from their social environment.

To assess the relationships between the psychosocial factors and the mental health sub-scales of the RAND-36, a regression analyses was used-see Table 2.

Table 2 shows that the level of social functioning, the amount of role limitations due to emotional problems, the level of mental health scores and the level of vitality can be partly explained by variations in the psychosocial factors studied. In all cases the degree of loneliness and the level of generalized self-efficacy significantly contribute to the explanation of aforementioned mental aspects of quality of life. The level of support with problems also significantly contributes to the explanation of mental health.

Table 2. Regression coefficients with the sub-scales of the RAND-36 as dependent variables and loneliness, social mobilization, self-efficacy, daily support, support with problems and esteem support as predictors

\begin{tabular}{lcccc}
\hline Predictors & $\begin{array}{c}\text { Social } \\
\text { functioning }\end{array}$ & $\begin{array}{c}\text { Limitations } \\
\text { (emotional) }\end{array}$ & $\begin{array}{c}\text { Mental } \\
\text { health }\end{array}$ & Vitality \\
\hline $\begin{array}{l}\text { Social } \\
\text { mobilization }\end{array}$ & 0.020 & -0.018 & 0.041 & 0.094 \\
$\begin{array}{l}\text { Loneliness } \\
\text { Self-efficacy }\end{array}$ & $0.211^{3}$ & $0.142^{3}$ & $0.283^{3}$ & $0.183^{3}$ \\
Support with & $0.242^{3}$ & $0.318^{3}$ & $0.374^{3}$ & $0.374^{3}$ \\
$\quad$ problems & 0.017 & 0.009 & 0.118 & 0.110 \\
Esteem & -0.107 & -0.123 & $-0.135^{1}$ & -0.106 \\
$\quad$ support & -0.014 & -0.042 & -0.110 & -0.094 \\
\hline R-square & & & & \\
\hline
\end{tabular}

${ }^{1} p<0.05:{ }^{2} p<0.01:{ }^{3} p<0.001$ 


\section{Discussion}

Results of this study of 480 cancer patients who had been aware of the cancer diagnosis for 2.5 years, show that the average scores on mental health aspects of quality of life in these patients are only slightly lower than the average scores obtained by a reference group from the general population. In general, there are no indications that the mental health of these cancer survivors is severely affected. Multiple regression analysis showed that level of loneliness and generalized self-efficacy are the psychosocial factors that are most closely linked to the level of mental health among cancer survivors.

The aim of this study was to analyse psychosocial factors that are related to mental health of cancer patients. Assessing the relative importance of psychosocial factors in the mental health of cancer patients may contribute to the design of an effective health promotion programme aimed at reducing psychosocial problems among cancer patients.

Mental health aspects of the quality of life of cancer survivors compared to a reference group from the general population, reveals only slightly lower scores of the cancer survivors with respect to the mental health aspects of quality of life. Results from this study show that feelings of loneliness and level of generalized self-efficacy are the major predictors of the variations in the mental health of cancer survivors.

The cross-sectional research design used in this study restricts definitive conclusions about the causal relation between the psychosocial factors and either the amount of psychosocial problems or mental health aspects of quality of life. The level of generalized selfefficacy showed a significant correlation with both the amount of psychosocial problems and mental health. It can, however, not be excluded that the amount of psychosocial problems and the mental health status of the patient can severely affect the level of generalized self-efficacy. A more definite conclusion about the relation between generalized self-efficacy and mental health could be obtained from longitudinal research designs using structural equation models (Jöreskog \& Sörbom, 1988).

Nevertheless the results are supportive of the idea that self-management strategies used by patients are related to the mental health status of cancer patients. Improving self-management strategies among cancer patients may prove to be a possibly effective health promotion method in cancer patients. In a previous publication (Seydel et al., 1994), an outline was given of a method to improve self-efficacy and self-management strategies among patients. This method has been applied to patients with rheumatoid arthritis (Taal et al. 1993) and a adapted version of the method could be designed for cancer patients. In the development of this method special attention should be given to strengthen the skills of the patient which promote the feeling of control over the serious situation with which they are confronted. Several authors have made suggestions that might be helpful is this respect (see among others, Cunningham et al., 1991; Meyerowitz, 1980; Redd \& Hendler, 1983; Telch \& Telch, 1985).

\section{Acknowledgements}

This study was financed by the Comprehensive Cancer Centre Enschede, The Netherlands. The authors acknowledge the assistance and co-operation of A.G. Boekema. MD and the hospital Twenteborg Ziekenhuis Almelo and the hospital Ziekenhuiscentrum Apeldoorn.

\section{References}

BANDURA, A. (1986). Social foundations of thought and action: a social cognitive theory. Englewood Cliffs, NJ: PrenticeHall. 
BoER, H. (1993). Psychosociale aspecten van bevolkingsonderzoek naar borstkanker (Psychosocial aspects of breast cancer screening). Dissertation. Enschede: University of Twente.

Boer, H., Seydel, E.R., Van Rij, K., Boekema, A.G. \& MAK, A.C.A. (1992). Psychosociale problemen van recent gediagnosticeerde borstkankerpatienten (Psychosocial problems of recently diagnosed breast cancer patients). Gedrag \& Gezondheid, 20(6), 297-305.

Brook, R.J., Ware, J.E., Davies-Avery, A., StT, A. Donald, C.A., Rogers, W.H., Williams, K.N. \& Johnson, S.A. (1979). Overview of adult health status measures in RAND's Health Insurance Study. Medical Care. 15, 724-735.

BRUNER, D.W. (1995). In search of the 'quality' in Quality of Life research. International Foumal of Radiation Oncology, Biology, Physics. 31, 191-192.

Cassileth, B.R., Lusk, E.J., Strouse, T.B., Miller, D.D., Brown, L.L., Cross, P.A. \& Tenaglia, A.N. (1984). Psychosocial status in chronic illness: a comparative analysis of six diagnostic groups. The New England foumal of Medicine, 8, 506-511.

Cunningham, A.J., Lockwood, G.A. \& Cunningham, J.A. (1991). A relationship between perceived self-efficacy and quality of life in cancer patients. Patient Education \& Counseling, 17, 71-78.

De Jong-Gierveld, J. (1987). Developing and testing a model of loneliness. Fournal of Personality and Social Psychology, 53(1), 119-128.

DUNKEL-SCHETTER, C. (1984). Social support and cancer: findings based on patient interview and their implications. fournal of Social Issues, 40, 77-98.

Friedman, L.C., Baer, P.E., Lewy, A., Lane, M. \& SMIth, F.E. (1989). Predictors of psychosocial adjustment to breast cancer. fournal of Psychosocial Oncology, 6, 75-94.

Funch, D.P. \& METTLIN, C. (1982). The role of support in relation to recovery from breast surgery. Social Science and Medicine, 16, 91-98.

Grieco, A. \& LoNG, C.J. (1984). Investigation of the Karnofsky Performance Status as a measure of quality of life. Health Psychology, 3, 129-142.

Hol LAND, J.C. \& LESKO, L.M. (1988). Chemotherapy, endocrine therapy, and immunotherapy. In: J.C. Holl.AND \& J.H. ROWLAND (Eds), Handbook of psychooncology: psychological care of the patient with cancer (pp. 146-162). Oxford: Oxford University Press.

JeRUSAlem, M. \& SCHWARZER, R. (1992). Self-efficacy as a resource factor in stress appraisal processes. In: R. SCHWARZER (Ed.). Self-efficacy: thought control of action (pp. 195-213). Washington, DC: Hemisphere.

JORESKog, K.G. \& SORBOM, D. (1988). LISREL 7: $A$ guide to the program and applications. Chicago Ill: SPSS Inc.

KNOBF, M.T. (1990). Symptoms and rehabilitation needs of patients with early stage breast cancer during primary therapy. Cancer, 66, 1392-1401.

LAZARUs, R.S. (1966). Psychological stress and the coping process. New York: McGraw-Hill.

MEYerowITZ, B.E. (1980). Psychosocial correlates of breast cancer and its treatment. Psychological Bulletin, 87, 108-131.

NoRThHouse, L.L. (1988). Social support in patients' and husbands' adjustment to breast cancer. Nursing Research, $37,91-95$.

Peters-Golden, H. (1982). Breast cancer: varied perceptions of social support in the illness experience. Social Science and Medicine, 16, 483-491.

REDD, W.H. \& HENDLER, C.S. (1983). Behavioral medicine in comprehensive cancer treatment. fournal of Psychosocial Oncology, 1, 3-17.

RIEMSMA, R.P., ElVING, W.J.L., TAAL, E. \& BoER, H. (1997). Constructie en evaluatie van de sociale mobilisatieschaal (Construction and evaluation of the social mobilization scale). Gedrag $\mathcal{E}$ Gezondheid (in press).

Ros, W.J.G., WINNUBST, J.A.M. \& CouZIN, A.L. (1992). The effects of social support on cancer patients: coping style and stage of illness as moderators. In: J.A.M. WINNUBST \& S. MAES (Eds), Lifestyles, stress and health (pp. 247-257). Leiden: DSWO Press.

RoWLAND, J.H. (1988). Interpersonal resources: coping. In: J.C. HoLLAND \& J.H. Rowland (Eds), Handbook of psychooncology: psychological care of the patient with cancer (pp. 44-57). Oxford: Oxford University Press.

Schag, C.A.C., HeInRICH, R.L., Aadland, R.L. \& Ganz, P.A. (1990). Assessing problems of cancer patients: psychometric properties of the cancer inventory of problem situations. Health Psychology, 9, 83-102.

SCHWARZER, R. \& FUCHS, R. (1996). Self-efficacy and health behaviours. In: M. CoNNER \& P. NoRMAN (Eds), Predicting health behaviour: research and practice with social cognition models (pp. 163-196). Buckingham: Open University Press.

SeYdel, E.R., TAal, E. \& BoeR, H. (1994). Patient education: self-efficacy and self-management strategies. In: J.P. Dauwalder (Ed.), Psychology and promotion of health (pp. 94-101). Seattle: Hogrefe \& Huber Publishers.

Silberfarb, P.M., Mauser, H. \& Crouthamel, C.S. (1980). Psychosocial aspects of neoplastic disease: 1: Functional status of breast cancer patients during different treatment regimens. American fournal of Psychiatry, 137, 450-455. 
Smith, E.M., Redman, R., Burns, T.L. \& Sagert, K.M. (1985). Perceptions of social support among patients with recently diagnosed breast, endometrial and ovarian cancer: an exploratory study. fournal of Psychosocial Oncology, 3, 65-81.

TAAL, E., SEydel, E.R., Riemsma, R., Brus, H.L.M., RaskeR, J.J. \& Wiegman, O. (1994). Group self-management training for patients with rheumatoid arthritis. In: J.P. DAUWALDER (Ed.), Psychology and promotion of health (pp. 112-120). Seattle: Hogrefe \& Huber Publishers.

TAYLOR, S.E., LichTMANN, R.R. \& WOOD, J.V. (1984). Attributions, beliefs about control and adjustment to breast cancer. Foumal of Personality and Social Psychology, 46, 489-502.

TELCH, C.H. \& TELCH, M.J. (1986). Group coping skills instruction and supportive group therapy for cancer patients. fournal of Consulting and Clinical Psychology, 54, 802-808.

VAN EIJK, L.M., KEMPEN, G.I.J.M. \& VAN SONDEREN, F.L.P. (1994). Een korte schaal voor het meten van sociale steun bij ouderen (A short scale for the measurement of social support in the elderly). Tijdschrift voor Gerontologie en Geriatrie, 25(5), 192-196.

VAN DER ZEE, K. \& SANDERMAN, R. (1994). Het meten van de algemene gezondheidstoestand met de Rand-36: een handleidleiding (The measurement of the general Health Status with the RAND-36: a guide). Groningen: Nothern Centre for Healthcare Research.

WeIsman, A.D. (1977), A model for psychosocial phasing in cancer. In: R. Moos (Ed.), Coping with physical illness. New York: Plenum Press.

WortMan, C.B. (1984). Social support and the cancer patient: conceptual and methodologic issues. Cancer, 53 (Suppl.), 2339-2360.

Zemore, R. \& SHEPEL, L.F. (1987). Information seeking and adjustment to cancer. Psychological Reports, $60,874$. 